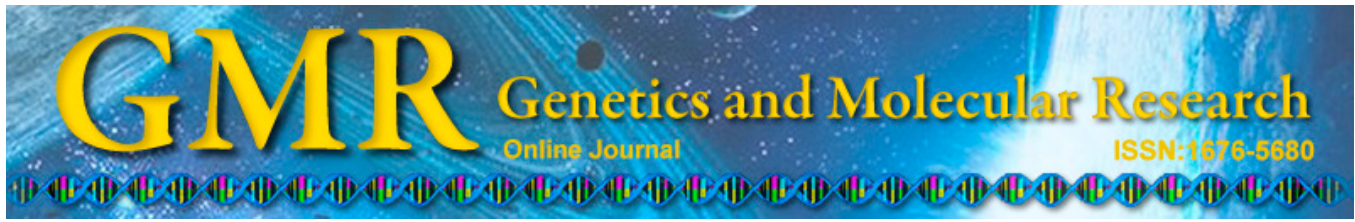

\title{
Isolation and characterization of simple sequence repeat markers for the herbaceous species Phyla scaberrima (Verbenaceae)
}

\author{
C.L. Chaves ${ }^{1 *}$, E.A. Ruas $^{2 *}$, C.F. Ruas ${ }^{2}$, J. Delfini ${ }^{1}$, N.C. Bejatto ${ }^{1}$, \\ B.D. Góes ${ }^{1}$ and P.M. Ruas ${ }^{2}$ \\ ${ }^{1}$ Departamento de Agronomia, Centro de Ciências Agrárias, \\ Universidade Estadual de Londrina, Londrina, PR, Brasil \\ ${ }^{2}$ Departamento de Biologia Geral, Centro de Ciências Biológicas, \\ Universidade Estadual de Londrina, Londrina, PR, Brasil \\ *These authors contributed equally to this study. \\ Corresponding author: P.M. Ruas \\ E-mail: ruas@uel.br
}

Genet. Mol. Res. 13 (3): 7864-7868 (2014)

Received May 17, 2014

Accepted September 12, 2014

Published September 26, 2014

DOI http://dx.doi.org/10.4238/2014.September.26.24

\begin{abstract}
Phyla scaberrima (Verbenaceae) is a herbaceous species distributed from Mexico to Panama. Because of its well-known sweet properties and other medicinal uses, this species is cultivated in South America and the Caribbean. Phyla scaberrima has been arbitrarily extracted from nature, resulting in a severe reduction in its gene pool. In this study, we developed and characterized 11 simple sequence repeat markers for $P$. scaberrima to determine the genetic variability and patterns of population structure of the species. Fifty-six alleles were detected in a sample of 48 individuals belonging to 3 different populations. The average number of alleles per locus was 5.09, while the polymorphic information content ranged from $0.000-0.587$. The observed and expected heterozygosities varied from $0.000-0.543$ and from 0.000-0.651, respectively. Two loci exhibited significant deviation of the expected Hardy-Weinberg proportion. The 11 primer pairs were
\end{abstract}


also tested for cross-amplification to 6 species of the related genus Lippia. The transferability rate ranged from 4 loci in Lippia florida and $L$. rotundifolia to 6 loci in L. corymbosa and L. microcephala. The 11 primer sets were shown to be valuable tools for population genetic studies in P. scaberrima and in species of the genus Lippia in which primer transferability was detected.

Key words: Aztec sweet herb; Medicinal species; Microsatellites markers; Primers

\section{INTRODUCTION}

Phyla scaberrima (Juss. ex Pers.) Moldenke, formerly known as Lippia dulcis and Phyla dulcis, is an herbaceous perennial species that belongs to the Verbenaceae family (Plant List, 2013; Tropicos, 2014). This species is naturally distributed from Mexico to Panama and is cultivated in South America, the Andes, Antilhas (Pascual et al., 2001), and the Caribbean. $P$. scaberrima grows in forest edges, river banks, open fields, and pastures at altitudes ranging from the sea level up to $1800 \mathrm{~m}$ (Cáceres, 1999, 2006).

P. scaberrima is also known by the common names of Aztec sweet herb or Orozul because of its sweet taste that is approximately 1000 times higher than sugar from Saccharum officinalis. The sweet property of $P$. scaberrima is attributed to the presence of hernandulcin and $4 \beta$-hidroxihernandulcin. This species also shows anti-inflammatory, antispasmodic, and antibiotic properties (Souto-Bachiller et al., 1997), as well as inhibits murine melanoma, gastric adenocarcinoma, and uterine carcinoma (Fumiko et al., 2002).

Medicinal plants are very important in developing countries, as they are often included in social health programs (Soler, 2005; Hoeffel et al., 2011). Thus, P. scaberrima has been exploited by a very long time for use in natural medicine to treat infections, particularly those related to the respiratory tract (Diseldorff, 2009). The main consequence of this indiscriminate extraction has been a loss of genetic variability because of the drastic reduction in natural populations.

Simple sequence repeat (SSR) markers are commonly used in studies of genetic variability at the population level because of their codominant pattern, high levels of polymorphism, and high levels of reproducibility (Ferreira and Gattapaglia, 1998). The main goal of this study was to develop and characterize microsatellite loci for P. scaberrima for future population genetic studies and to guide strategies for conserving the genetic resources of this species.

\section{MATERIAL AND METHODS}

Genomic DNA from P. scaberrima was extracted using the cetyltrimethyl ammonium bromide (CTAB) protocol (Doyle and Doyle, 1987). An enriched microsatellite library was developed for 1 individual of $P$. scaberrima using the hybridization method with biotin-labeled (CT) $)_{8}$ and $(\mathrm{GT})_{8}$ (Billotte et al., 1999). Approximately $5 \mu \mathrm{g}$ genomic DNA was digested with RsaI (Promega, Madison, WI, USA), and blunt-ended fragments were linked to adapters (Rsa21 and $R s a 25$ ). Fragments containing repeats were selected by hybridization with the bio- 
tinylated oligonucleotides and recovered using streptavidin-coated magnetic beads (Invitrogen, Carlsbad, CA, USA). Microsatellite-rich fragments were amplified by polymerase chain reaction (PCR) using the Rsa21 adapter as a primer, cloned into the pGEM-T Easy vector (Promega), and transformed into Escherichia coli XL1Blue MRF supercompetent cells (Agilent Technologies, Stratagene Products Division, La Jolla, CA, USA).

Plasmids were isolated and sequencing reactions were performed through subsequent purifications. Sequences were determined using a 3500XL Genetic Analyzer (Applied Biosystems, Foster City, CA, USA). Sequences were analyzed using the program Gramene (Ware et al., 2002) to identify regions containing microsatellites and primers were designed using the program PRIMER3 version 0.4.0 (Rozen and Skaletsky, 2000). A total of 16 primer pairs were designed and tested for amplification. Amplification failed with 5 primers, while 11 primers showed clear and consistent amplification patterns and were used for further analysis.

PCR amplification and the consistency of each primer pair were tested in a sample of 48 individuals from 3 populations of $P$. scaberrima. Reactions contained $4.5 \mu \mathrm{L} \mathrm{GoTaq}$ Green Master Mix (Promega), $0.08 \mu \mathrm{L}$ M13 tailed forward primer, $0.32 \mu \mathrm{L}$ reverse primer (Table 1), and M13 primer labeled with fluorophors, and DNA samples consisted of $10 \mathrm{ng}$ PdulD12 and PdulE08 primers, 25 ng PdulG11, and PdulG12 primers, 50 ng Pdul4, Pdul8, Pdul10, PdulF12, and PdulG08 primers, 30 ng PdulC12 primer, and 75 ng PdulB12 primer; the final reaction volume was adjusted to $10 \mu \mathrm{L}$ with nuclease-free water.

PCR profiles consisted of a touchdown program with the initial annealing temperature at $65^{\circ} \mathrm{C}$ for each primer and PCR cycling parameters of: 1 cycle of $94^{\circ} \mathrm{C}$ for $4 \mathrm{~min}$, followed of 12 cycles at $94^{\circ} \mathrm{C}$ for $30 \mathrm{~s}, 65^{\circ} \mathrm{C}$ for $30 \mathrm{~s}$ with a linear decrease of $1^{\circ} \mathrm{C}$ per cycle for the annealing temperature until reaching $55^{\circ} \mathrm{C}$, followed by 29 additional cycles at $94^{\circ} \mathrm{C}$ for $30 \mathrm{~s}, 55^{\circ} \mathrm{C}$ for $30 \mathrm{~s}$, and $72^{\circ} \mathrm{C}$ for $30 \mathrm{~s}$; a cycle of $94^{\circ} \mathrm{C}$ for $30 \mathrm{~s}, 54^{\circ} \mathrm{C}$ for $30 \mathrm{~s}$, and $72^{\circ} \mathrm{C}$ for $30 \mathrm{~s} ; 7$ cycles at $94^{\circ} \mathrm{C}$ for $30 \mathrm{~s}, 53^{\circ} \mathrm{C} 45 \mathrm{~s}$, and $72^{\circ} \mathrm{C}$ for $45 \mathrm{~s}$; final extension at $60^{\circ} \mathrm{C}$ for $40 \mathrm{~min}$.

PCR products were separated in an automatic sequencer 3500xl (Applied Biosystems). Genetic analysis of the fragments was carried out using the GeneMapper 4.0 software (Applied Biosystems). For data analysis, we applied standard population genetic statistics using Cervus version 3.0.3 (Kalinowski et al., 2007) and Fstat version 2.9.3.2 (Goudet, 2001) to test for linkage disequilibrium using Fisher's method $(\alpha=0.05)$ with 1100 permutations. We also determined the presence of null alleles, which generally cause deviations from Hardy-Weinberg equilibrium at microsatellite loci (Pemberton et al., 1995), applying the MicroChecker software (van Oosterhout et al., 2004).

\section{RESULTS AND DISCUSSION}

To characterize the 11 loci selected, we genotyped 48 individuals of $P$. scaberrima representing native populations of Colombia and Mexico. Samples consisted of 15 individuals of 2 populations from Mexico (Atzalan 19 $9^{\circ} 5^{\prime} 32^{\prime \prime} \mathrm{N}, 97^{\circ} 12^{\prime} 36^{\prime \prime} \mathrm{W}$, altitude of $600 \mathrm{~m}$ and Misantla $19^{\circ} 58^{\prime} 00^{\prime \prime} \mathrm{N}, 96^{\circ} 52^{\prime} 48^{\prime \prime} \mathrm{W}$, altitude of $120 \mathrm{~m}$ ), and 33 individuals from Colombian populations (Cali $3^{\circ} 26^{\prime} 48.75^{\prime \prime} \mathrm{N}, 76^{\circ} 37^{\prime} 46.39^{\prime \prime} \mathrm{W}$, altitude of $1525 \mathrm{~m}$; Dagua $3^{\circ} 35^{\prime} 5.04^{\prime \prime} \mathrm{N}, 76^{\circ} 38^{\prime} 58.25^{\prime \prime} \mathrm{W}$, altitude of $1468 \mathrm{~m}$; and Pereira $4^{\circ} 45^{\prime} 34.00^{\prime \prime} \mathrm{N}, 7^{\circ} 37^{\prime} 46.67^{\prime \prime} \mathrm{W}$, altitude of $1302 \mathrm{~m}$ ). The sequences of the 11 microsatellite loci were submitted to Genbank and registered under the accession numbers cited in Table 1. 


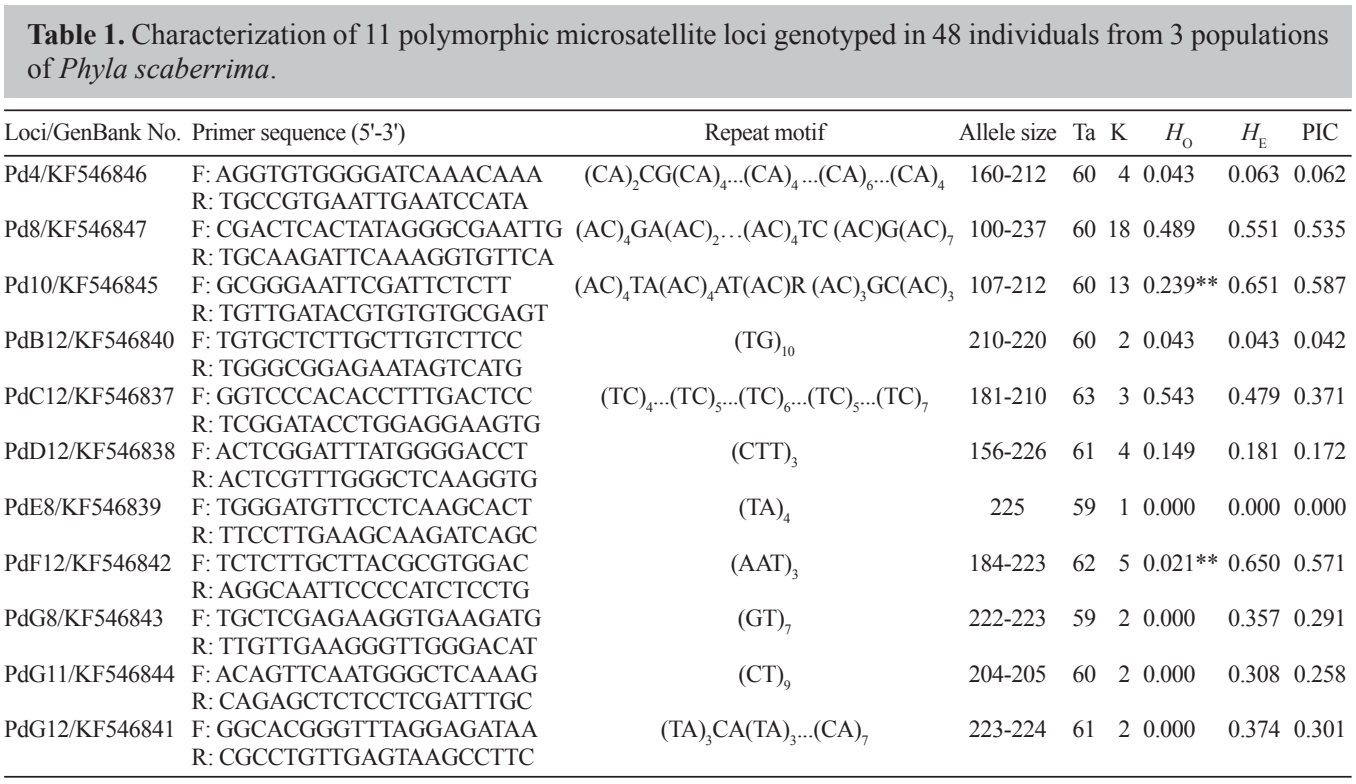

Allele size indicates the range of observed alleles in bp; $\mathrm{Ta}=$ annealing temperature $\left({ }^{\circ} \mathrm{C}\right) ; \mathrm{K}=$ number of alleles; $H_{\mathrm{O}}$ and $H_{\mathrm{E}}=$ observed and expected heterozygosities, respectively; PIC = polymorphic information content. **Significant deviation from Hardy-Weinberg equilibrium with $\mathrm{P} \leq 0.001$.

Genotyping of 48 individuals of $P$. scaberrima identified a total of 56 alleles and a moderate polymorphism level. The number of alleles ranged from 1 (PdE8) to 18 (Pd8), with an average of 5.09 alleles per locus (Table 1) and average polymorphic information content ranging from 0.000-0.587. The observed and expected heterozygosities for each locus ranged from $0.000-0.543$ and from $0.000-0.651$, with mean values of 0.139 and 0.332 , respectively (Table 1). Pairwise comparisons for multiple tests showed no significant linkage disequilibrium between loci, while the null allele was observed for locus PdE8.

The 11 selected primers were tested for cross-amplification in 6 species of the related genus Lippia (Table 2). The primer pairs PdB12, PdC12, and PdG12 showed inconsistent amplification for all species tested, while the locus PdF12 showed amplification only in Lippia

\begin{tabular}{|c|c|c|c|c|c|c|}
\hline Species & Lippia alba & Lippia corymbosa & Lippia florida & Lippia microcephala & Lippia rosella & Lippia rotundifolia \\
\hline \multicolumn{7}{|l|}{$\begin{array}{l}\text { Locus } \\
\end{array}$} \\
\hline $\mathrm{Pd} 4$ & - & + & - & - & - & + \\
\hline $\mathrm{Pd} 8$ & - & + & + & + & + & + \\
\hline Pd10 & - & + & - & + & - & + \\
\hline $\mathrm{PdB} 12$ & - & - & - & - & - & - \\
\hline $\mathrm{PdC} 12$ & - & - & - & - & - & - \\
\hline PdD12 & - & - & + & + & - & - \\
\hline PdE8 & - & + & + & + & + & + \\
\hline PdF12 & - & - & - & - & + & - \\
\hline PdG8 & - & + & + & + & + & + \\
\hline PdG11 & - & + & - & + & - & - \\
\hline PdG12 & - & - & - & - & - & - \\
\hline
\end{tabular}

$(+)=$ clear amplification; $(-)=$ no amplification. 
rosella Moldenke. Loci Pd4, PdD12, and PdG11 were amplified in 2 species and locus Pd10 was amplified in 3 species, while loci Pd8, PdE8, and PdG8 showed consistent amplification in 5 species. Lippia alba (Mill.) N.E.Br. ex Britton \& P.Wilson showed no amplification for all loci tested. Species showing higher levels of amplification included Lippia microcephala Cham. and P. corymbosa Cham. with 6 loci.

The development of SSR markers is an important step in understanding the consequences of predatory extraction that have affected the genetic variability of $P$. scaberrima. Cross-amplification for species of the genus Lippia showed the potential of these markers to be utilized for population genetics studies of these species.

\section{ACKNOWLEDGMENTS}

Research supported by Fundação Araucária and CAPES.

\section{REFERENCES}

Billotte N, Lagoda PJR, Risterucci AM and Baurens FC (1999). Microsatellite-enriched libraries: applied methodology for the development of SSR markers in tropical crops. Fruits 54: 277-288.

Cáceres A (1999). Plantas de Uso Medicinal en Guatemala (Girón L and Cáceres A, eds.). Editorial Universitaria, Guatemala.

Cáceres A (2006). Propuesta de Monografias Farmacopeicas de 10 Plantas Medicinales Centroamericanas. OEA-AID (Organización de Estados Americanos OEA; Agencia Interamericana de Cooperación para el Desarrollo AICD). Guatemala.

Diseldorff NG (2009). Phyla dulcis (Trevir.) Moldenke: Descripción de Características Anatómicas Diagnósticas de la Droga Cruda. Master's thesis, Universidad de San Carlos de Guatemala Facultad de Ciencias Quimicas y Farmacia, Guatemala.

Doyle JJ and Doyle JL (1987). A rapid isolation procedure for small quantities of fresh leaf tissue. Phytochem. Bull. Res. 19: 11-15.

Ferreira WC and Grattapaglia D (1998). Introdução ao Uso de Marcadores Moleculares em Análise Genética. Embrapa, Cenargem, Brasilia.

Fumiko A, Tsuneatsu N and Hikaru O (2002). Antiproliferative constituents in plants 9.1 aerial parts of Lippia dulcis and Lippia canescens. Biol. Pharm. Bull. 25: 920-922.

Goudet J (2001). FSTAT, A Program to Estimate and Test Gene Diversity and Fixation Indices. Version 2.9.3.2. Available at [http://www2.unil.ch/popgen/softwares/fstat.htm]. Accessed December 24, 2013.

Hoeffel JLM, Gonçalves NM, Fadini AAB and Seixas SRC (2011). Conhecimento Tradicional e Uso de Plantas Medicinais nas Apas's Cantareira/SP e Fernão Dias/MG. Revista Vitas: Visão Transdisciplinares sobre Ambiente e Sociedade, 1-25.

Kalinowski ST, Taper ML and Marshall TC (2007). Revising how the computer program CERVUS accommodates genotyping error increases success in paternity assignment. Mol. Ecol. 16: 1099-1106.

Pascual ME, Slowing K, Carretero E, Sánchez Mata D, et al. (2001). Lippia: tradicional uses, chemistry and pharmacology: a review. J. Ethnopharm. 76: 201-241.

Pemberton JM, Slate J, Bancroft DR and Barrett JA (1995). Nonamplifying alleles at microsatellite loci: a caution for parentage and population studies. Mol. Ecol. 4: 249-252.

Plant List (2013). Phyla scaberrima (Juss. ex Pers.) Moldenke. Available at [http://www.theplantlist.org/tpl1.1/record/ kew-153231]. Accessed March 21, 2014.

Rozen S and Skaletsky HJ (2000). Primer3: Bioinformatics Methods and Protocols. In: Methods in Molecular Biology (Krawetz S and Misener S, eds.). Humana Press, New York, 365-386.

Soler BA II (2005). Monografías sobre Plantas. Documento de Apoyo para el Curso de Farmacognosia de la Maestría Multidisciplinaria en Uso y Producción de Plantas Medicinales MUPLAM de la Universidad de San Carlos de Guatemala, Guatemala.

Souto-Bachiller FA, Jesus-Echevarria M, Cardenas-Gonzalez OE, Acuna-Rodriguez MF, et al. (1997). Terpenoid composition of Lippia dulcis. Phytochemistry 44: 1077-1086.

Tropicos (2014). Phyla scaberrima (Juss. ex Pers.) Moldenke. Available at [http://www.tropicos.org/Name/33700802]. Accessed March 21, 2014.

Ware D, Jaiswal P, Ni J, Pan X, et al. (2002). Gramene: a resource for comparative grass genomics. Nucleic Acids Res. 30: 103-105. 